\title{
Effects of Bilayer Period on the Microhardness and Its Strengthening Mechanism of CrN/AIN Superlattice Coatings
}

\author{
SungMin $\mathrm{Kim}^{\dagger}$, EunYoung $\mathrm{Kim}^{\dagger}$, DongJun Kim, JoungHyun La, SangYul Lee* \\ Center for Surface Technology and Applications, Department of Material Engineering, \\ Korea Aerospace University, Gyunggi-Do 412-791, Korea
}

(Received December 7, 2012 ; revised December 28, 2012 ; accepted December 30, 2012)

\begin{abstract}
$\mathrm{CrN} / \mathrm{AlN}$ multilayer coatings with various bilayer periods in the range of 1.8 to $7.4 \mathrm{~nm}$ were synthesized using a closed-field unbalanced magnetron sputtering method. Their crystalline structure, chemical compositions and mechanical properties have been investigated with Auger electron spectroscopy, X-ray diffractometry, atomic force microscopy, nanoindentation, scratch tests. The properties of the multilayer coatings varied strongly depending upon the magnitude of the bilayer period. The multilayer coating with a bilayer period of $1.8 \mathrm{~nm}$ showed the maximum hardness and an elastic modulus of approximately 37.6 and $417 \mathrm{GPa}$, respectively, which was 1.54 times higher than the hardness predicted by the rule of mixture from the $\mathrm{CrN}$ and AIN coatings. The hardness of the multilayer coating increased as the bilayer period decreased, i.e. as the rotation speed increased. The Hall-Petch type relationship, hardness being related to (1/periodicity) ${ }^{-1 / 2}$, suggested by Lehoczky was confirmed for the CrN/AlN multilayer coatings with bilayer period close to the 5-10 nm range. With decreasing bilayer period, the surface morphology of the films became rougher and the critical load of films for adhesion strength gradually decreased.
\end{abstract}

Keywords : CrN/AIN multilayer coating, Bilayer period, Hardness, Hall-Petch relationship

\section{Introduction}

Binary metal nitride films such as $\mathrm{TiN}, \mathrm{CrN}$, and $\mathrm{ZrN}$ made up the first generation of hard coatings. Since the mid-seventies, these nitrides have been exploited commercially for various cutting and tool applications due to their high hardness, high toughness, excellent chemical inertness, and good oxidation resistance. Likewise, their attractive appearance led to them being utilized for a large number of decorative applications ${ }^{1-5)}$. However, the mechanical properties of these binary metal nitrides at high temperatures degrade very rapidly as the porous oxides form at the film surface, especially above $600^{\circ} \mathrm{C}^{6}$. Naturally then, the next step in the development of PVD hard coatings was to improve the temperature resistance

\footnotetext{
The authors are equally contributed and EY Kim is now with Hyundai Hysco, Gyunggi-Do, South Korea
}

${ }^{*}$ Corresponding author. E-mail : sylee@kau.ac.kr of the thin films to make them more suitable for high temperature applications.

In order to overcome the problems inherent within binary coatings, a multi-component coating system with the addition of other elements such as $\mathrm{Cr}, \mathrm{Al}$, $\mathrm{Si}$, etc., into a binary system was investigated ${ }^{7-9)}$. For example, an extensive improvement in thermal stability and oxidation resistance of the CrAIN thin films could be obtained with the addition of the $\mathrm{Al}$ element into the $\mathrm{CrN}$ binary system ${ }^{7,8}$. Recently CrN/AlN multilayer coatings with various bilayer periods have been introduced for the improved mechanical, thermal and wear-resistant properties ${ }^{2,10-16)}$. Especially the oxidation resistance of the multilayer coatings is strongly affected by the bilayer period as well as the composition of the coatings.

However, the mechanical behavior of CrN/AIN superlattice films in terms of bilayer period needs further investigation and in this work, multilayerstructured thin films with various bilayer periods were synthesized by depositing two alternating $\mathrm{CrN}$ 
and AIN thin films. The improvement of the mechanical properties of the CrN/AIN films was then investigated. Focus will be drawn to the effect of various bilayer periods on the mechanical properties of the CrN/AlN multilayer coatings.

\section{Experimental Details}

CrN/AlN multilayer coatings were deposited on Si(100) wafer and nitrided AISI H13 steel using a closed-field unbalanced magnetron sputtering process with separated $\mathrm{Cr}$ and $\mathrm{Al}$ targets (round planar target: diameter $100 \mathrm{~mm}, \mathrm{t}=10 \mathrm{~mm}$ ). Prior to each coating being deposited, the substrates were cleaned ultrasonically using acetone. The base pressure of the sputtering chamber was pumped down to less than $6.6 \times 10^{-3} \mathrm{~Pa}$. During deposition, a constant $\mathrm{Cr}$ target power of DC $0.4 \mathrm{~kW}$ was maintained, and the discharge current of the $\mathrm{Al}$ target was maintained at unipolar pulse DC $1.8 \mathrm{~A}$ (frequency $20 \mathrm{kHz}$ and duty cycle $50 \%$ ), under which the thickness ratio of the $\mathrm{CrN}$ layer to the AIN layer becomes 1:1. Substrate rotation speed was varied from 3 to $12 \mathrm{rpm}$ to synthesize the films with various bilayer periods. The distance of target-to-substrate, substrate bias voltage and coating temperature were fixed to $60 \mathrm{~mm}, \mathrm{DC}-100 \mathrm{~V}$ and $150^{\circ} \mathrm{C}$, respectively. During the deposition process, the Ar pressure was set initially at $2.4 \times 10^{-3}$ Torr and the reactive gas of $\mathrm{N}_{2}$ was subsequently added to obtain the desired gas composition, maintaining a total working pressure of $4.4 \times 10^{-1} \mathrm{~Pa}$.

The chemical compositions of coatings were analyzed using the elemental depth profiles measured by Auger electron spectroscopy (AES: PHI 670). The crystal phase and bilayer period of the coatings were characterized by high-angle and low-angle X-ray diffraction (XRD: SEIFERT 3000PTS) with CuKa radiation. The intrinsic hardness $(H)$ and elastic modulus $(E)$ of the coatings were measured using a nanoindentation instrument (Nano-indenter XP: MTS instrument Co.) with a Berkovich diamond tip by fixing the indentation depth to $150 \mathrm{~nm}$, which was less than $10 \%$ of the total thickness of the film. The residual stress in the films was determined by wafercurvature measurements using a laser reflectance system, and the Stoney formula was used to calculate the residual stress in the films.

The surface morphologies were investigated using atomic force microscopy (AFM: Digital Instruments) and the critical load for the chipping of films (thickness: approximately $3.0 \mu \mathrm{m}$ ) was evaluated by using a scratch tester (revetest: CSEM) with a spherical diamond tip radius of $200 \mu \mathrm{m}$.

\section{Results and Discussion}

\subsection{Chemical composition and crystalline structure}

Fig. 1 illustrates the typical elemental depth profiles from the CrN/AlN multilayer coatings synthesized with a substrate rotation speed of $6 \mathrm{rpm}$. The periodicity due to a multilayer structure is clearly shown and it indicates that the processing conditions to synthesize CrN/AIN multilayer coatings with a 1:1 ratio were realized. Equally important is that carbon and oxygen elements were rarely found at any depth in the coating. This is indicative of the lack of carbon and oxygen contamination during deposition.

Results from the low-angle XRD analysis are shown in Fig. 2, and the bilayer period of the multilayer coatings were calculated from these patterns using the standard Bragg equation. As the substrate rotation speed decreased, the peaks became sharper and had

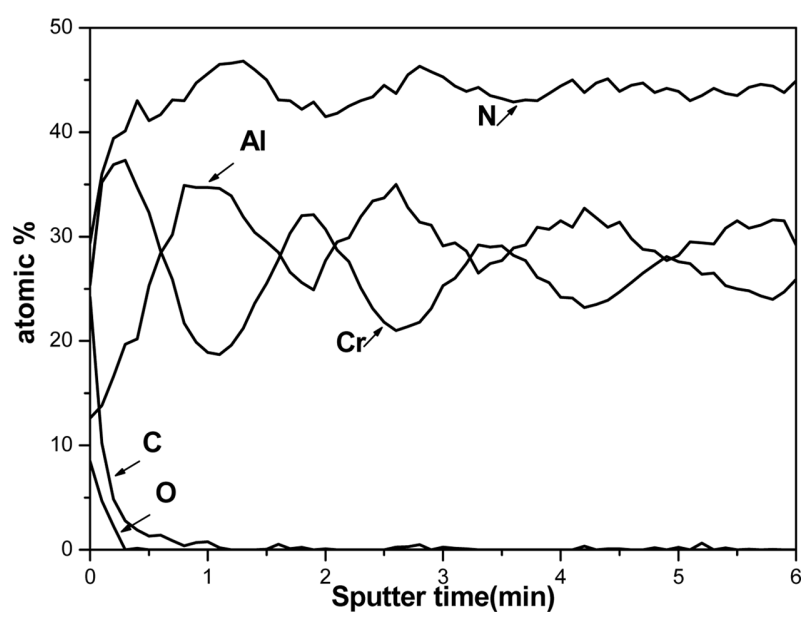

Fig. 1. Typical elemental depth profile of the CrN/AIN multilayer coatings with a substrate rotation speed of $6 \mathrm{rpm}$.

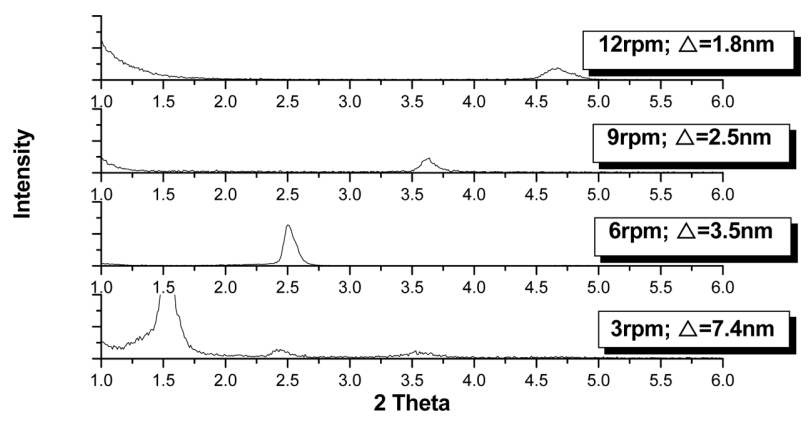

Fig. 2. Low-angle XRD patterns of the CrN/AIN multilayer coatings with various substrate rotation speeds. 


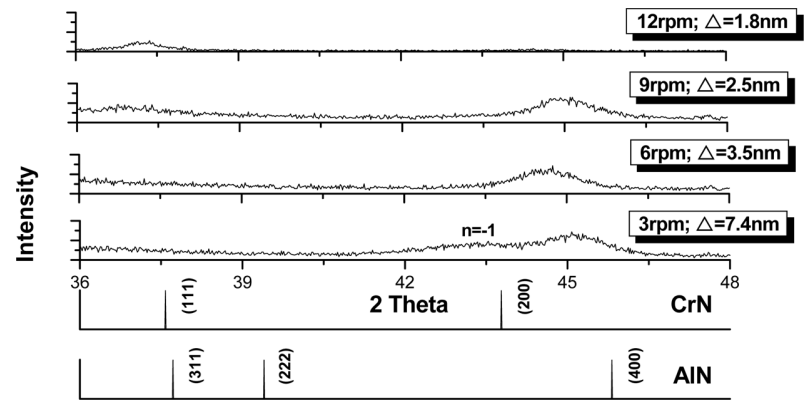

Fig. 3. High-angle XRD patterns of the CrN/AIN multilayer coatings with various substrate rotation speeds.

higher intensity. It became clear that the second and third order reflection appeared at substrate rotation speed of $12 \mathrm{rpm}$. This is due to the fact that the sharp interface between individual component layers in the film became defined without inter-diffusion among layers. They were $7.4 \mathrm{~nm}, 3.5 \mathrm{~nm}, 2.5 \mathrm{~nm}$, and $1.8 \mathrm{~nm}$ for the coatings synthesized with the substrate rotation speeds of $3,6,9$, and $12 \mathrm{rpm}$, respectively. Hence, the bilayer period decreases as the rotation speed increases.

The results from the high-angle XRD analysis on the coatings are shown in Fig. 3. The CrN/AlN multilayer coatings with substrate rotation speeds of 3, 6, and $9 \mathrm{rpm}$ showed a superlattice peak between the CrN (200) peak and the AlN (400) peak. Also observed was a satellite peak $(n=-1)$ from the $\mathrm{CrN} /$ AlN multilayer coatings synthesized with $3 \mathrm{rpm}$, as indicated in Fig. 3. This satellite reflection indicates that the multilayered coatings deposited at $3 \mathrm{rpm}$ have well-defined interfaces. However, no satellite peak was observed for the coatings synthesized with 6 and $9 \mathrm{rpm}$. It could be attributed to some level of interfacial mixing present between the $\mathrm{CrN}$ and $\mathrm{AlN}$ layers. Disappearance of the satellite peaks due to interfacial mixing has also been observed by other researchers $^{17,18)}$.

The CrN/AIN films synthesized with the highest rotation speed of $12 \mathrm{rpm}$ were expected to have an extensive degree of interfacial mixing. As expected, they did not show any superlattice peaks, but a diffraction peak at $2 \theta=37.3^{\circ}$ was observed, as shown in Fig. 3. Accordingly, this XRD pattern from the CrN/AlN films synthesized with the highest rotation speed of $12 \mathrm{rpm}$ was compared with those from the monolithic $\mathrm{Al}_{1-\mathrm{x}} \mathrm{Cr}_{\mathrm{X}} \mathrm{N}$ thin films $(\mathrm{X}=\mathrm{Cr} /$ $(\mathrm{Cr}+\mathrm{Al})$ in at.\%) with similar chemical compositions. The CrN/AlN coating synthesized with $12 \mathrm{rpm}$ has a corresponding $\mathrm{X}$ value of 0.45 and their high-angle XRD patterns were compared with those from the

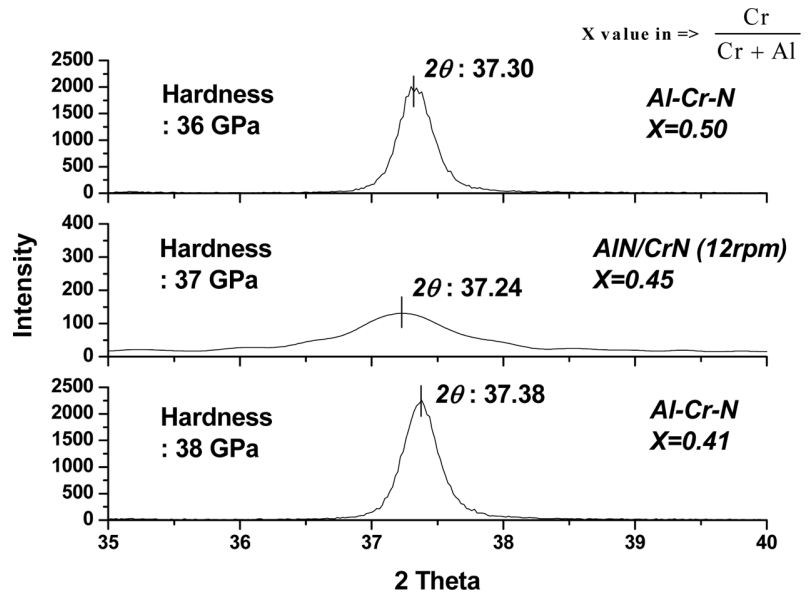

Fig. 4. Comparison of the high-angle XRD patterns from the CrN/AIN multilayer coatings with the monolithic Al-Cr-N coatings with similar chemical compositions.

monolithic $\mathrm{Al}_{1-\mathrm{x}} \mathrm{Cr}_{\mathrm{X}} \mathrm{N}$ coatings with $\mathrm{X}=0.41(27.05 \% \mathrm{Al}-$ $18.9 \% \mathrm{Cr}-54.1 \% \mathrm{~N})$ and $\mathrm{X}=0.50(22.65 \mathrm{Al}-22.8 \% \mathrm{Cr}-$ $54.6 \% \mathrm{~N})^{7}$, as shown in Fig. 4. It was interesting that not only the diffracted peaks at similar $2 \theta$ values, but also the similar hardness values from these thin films were observed. Based upon this observation, it is believed that due to a high substrate rotation speed, extensive interfacial mixing occurs between the layers and the coating synthesized with $12 \mathrm{rpm}$ was unable to form a clear multilayered thin film, but rather became a very fine microstructure, a mixture of the $\mathrm{CrN}$ and $\mathrm{AlN}$ phases. However, a detailed investigation using HR-TEM is necessary.

\subsection{Hardness}

The hardness and the elastic modulus of the $\mathrm{CrN} /$ AlN multilayer coatings with various bilayer periods were measured to be approximately 24.3 to $37.6 \mathrm{GPa}$ and approximately 278 to $407 \mathrm{GPa}$, respectively, as shown in Fig. 5. It was noted that the hardness of the multilayer coating increases as the bilayer period decreases, i.e. as the rotation speed increases. The CrN/AlN coatings with bilayer period of $1.8 \mathrm{~nm}$ (12 rpm) showed the maximum hardness and elastic modulus of approximately 37.6 and $407 \mathrm{GPa}$, respectively. It was approximately 1.54 times higher than the hardness predicted by the rule of mixture from $\mathrm{CrN}(23 \mathrm{GPa})$ and AlN (25 GPa) coatings. All other multilayer coatings with other rotation speeds showed a higher hardness than that predicted by the rule of mixture from the individual phases making up the multilayer coatings.

The strengthening mechanisms for the nanostructured 


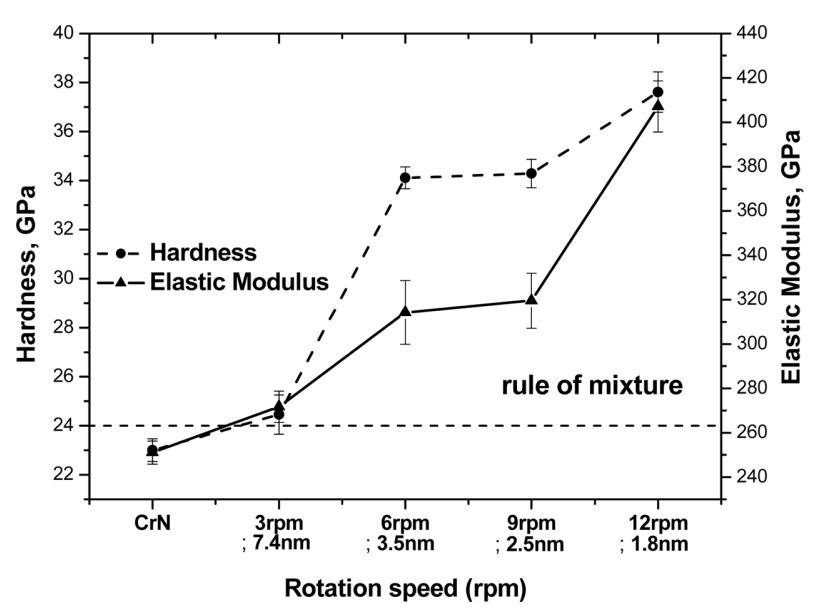

Fig. 5. Hardness and elastic modulus of the CrN/AIN multilayer coatings as a function of the substrate rotation speed.

multilayer coatings were predicted by the theoretical model by Koehler, which is based upon nano-scale multilayers consisting of two different materials with large differences in elastic moduli, sharp interface, and small bilayer period (or so-called "superlattice periods") of about 5-10 $\mathrm{nm}^{19}$. Koehler's concept was demonstrated experimentally by Lehoczky on the metallic $\mathrm{Al} / \mathrm{Cu}$ and $\mathrm{Al} / \mathrm{Ag}$ multilayers, and it was concluded that a Hall-Petch type relationship could be used to relate the hardness of the nanostructured multilayer coatings to $(1 / \text { periodicity })^{-1 / 2}$, where periodicity means a bilayer period or superlattice period ${ }^{20}$. This Hall-Petch type relationship had been confirmed in many systems, including metal/nitride and nitride/ nitride. Research was then focused on determining whether or not this Hall-Petch type relationship was applicable for the CrN/AlN multilayer coating with a bilayer period of approximately $5-10 \mathrm{~nm}$. As shown in Fig. 5, there was approximately a $10 \mathrm{GPa}$ improvement in hardness by varying the bilayer period from $7.4 \mathrm{~nm}$ (3rpm) to $3.5 \mathrm{~nm}$ (6rpm). As such, the validity of the relationship for this structural change to predict the hardness variation was examined. As the hardness of the multilayer coating is proportional to bilayer period $(\Delta)^{-1 / 2}$ in the Hall-Petch type relationship, the ratio of the hardness from the $\mathrm{CrN} /$ AlN coatings with bilayer period of $3.5 \mathrm{~nm}(6 \mathrm{rpm})$ to that with bilayer period of $7.4 \mathrm{~nm}(3 \mathrm{rpm})$ could be expressed:

$$
\frac{\mathrm{H}_{\Delta=3.5 \mathrm{~nm}}}{\mathrm{H}_{\Delta=7.4 \mathrm{~nm}}}=\frac{(3.5)^{-1 / 2}}{(7.4)^{-1 / 2}}=\frac{2.72}{1.87}=1.45
$$

i.e., according to the (1/periodicity $)^{-1 / 2}$ relationship, the hardness of the CrN/AIN coatings with bilayer period of $3.5 \mathrm{~nm}$ could be estimated to be 1.45 times of that of the coatings with bilayer period of $7.4 \mathrm{~nm}$. From the experimental data in Fig. 5, the hardness of the coatings with bilayer period of $3.5 \mathrm{~nm}, 34 \mathrm{GPa}$ was approximately 1.42 times of that with the coatings with bilayer period of $7.4 \mathrm{~nm}, 24 \mathrm{GPa}$, which is in good agreement with the estimated hardness ratio of 1.45 using the Hall-Petch type relationship.

As predicted in Koehler's concept, the hardness of the CrN/AlN multilayer coating did not seem to follow this Hall-Petch type relationship for very small bilayer period. By decreasing the bilayer period from 3.5 to $2.5 \mathrm{~nm}$, no hardness improvement was measured, as shown in Fig. 5. These measurements confirmed that there must exist a critical size range in which the Hall-Petch type relationship would be effectively applied, and the model would no longer be valid over the critical range, as suggested by Lehoczky ${ }^{20)}$.

The coherency strain or lattice mismatch at the interface could be utilized to explain the additional hardness increase in the coatings with small bilayer period or very fine microstructure. Large lattice parameter difference induces a large coherency strain at the interfaces, which in turn improves the hardness of the multilayer coatings by inhibiting the dislocation movement across the interfaces. Fig. 6 shows the results from the residual stress measurement as a function of the bilayer period. By decreasing the bilayer period from $2.5 \mathrm{~nm}(9 \mathrm{rpm})$ to $1.8 \mathrm{~nm}(12$ rpm), a large increase in the compressive residual stress in the coating was observed, which was expected due to the large lattice parameter difference. This residual stress in turn could be attributed to the large increase

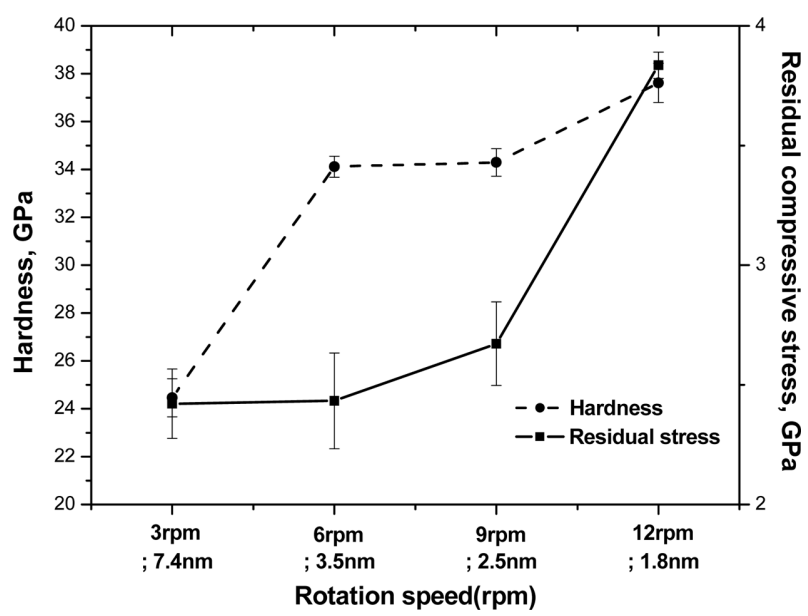

Fig. 6. Hardness and residual stress in the CrN/AIN multilayer coatings with various substrate rotation speeds. 
in the hardness of the CrN/AlN coating with bilayer period of $1.8 \mathrm{~nm}$ (12 rpm), compared with the coatings with bilayer period of $2.5 \mathrm{~nm}(9 \mathrm{rpm})$.

\subsection{Surface Morphologies and Adhesion strength}

The surface morphologies of films with various bilayer periods are shown in Fig. 7 With increasing rotation speed, the rms of the CrN/AIN thin films increased and the rms of the CrN/AlN thin films with bilayer period of $1.8 \mathrm{~nm}(12 \mathrm{rpm})$ was almost three time lager than that of the CrN/AIN thin films with bilayer period of $3.5 \mathrm{~nm}(6 \mathrm{rpm})$. The surface roughness increased with decreasing bilayer period, which is attributed to the larger grain size and higher degree of crystallization of CrN/AlN multilayer film. These observations are basically consistent with the results from multi-component coatings reported by other researchers ${ }^{21,22)}$.

Fig. 8 shows the critical load for the chipping of $\mathrm{CrN} / \mathrm{AlN}$ thin films with various bilayer periods and the high residual stress associated with thin films with a small bilayer period causes the low adhesion strength. All CrN/AlN films showed similar failure mode which cracks started to appear, which became more frequent at higher loads. This failure mechanism in CrN/AlN films is the result of adhesive failure due to the compressive stress. Therefore, the critical load of films gradually decreased with increasing compressive residual stress.

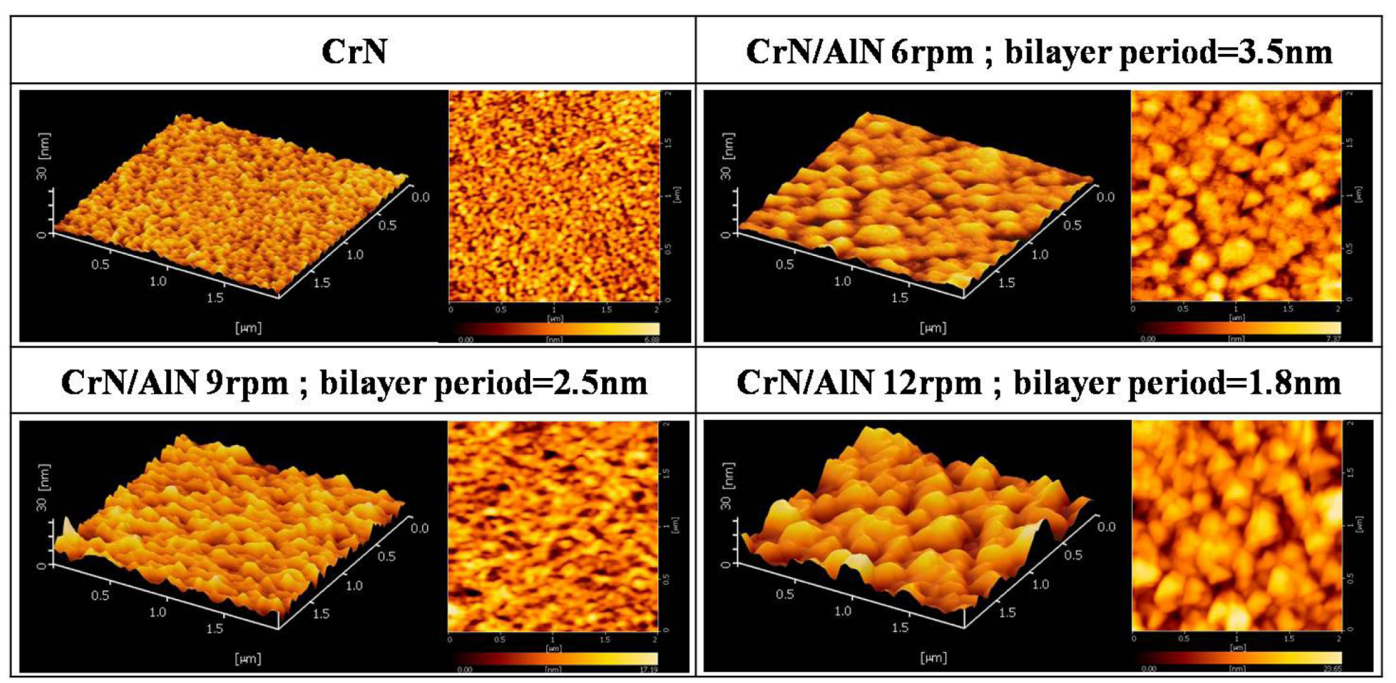

(a)

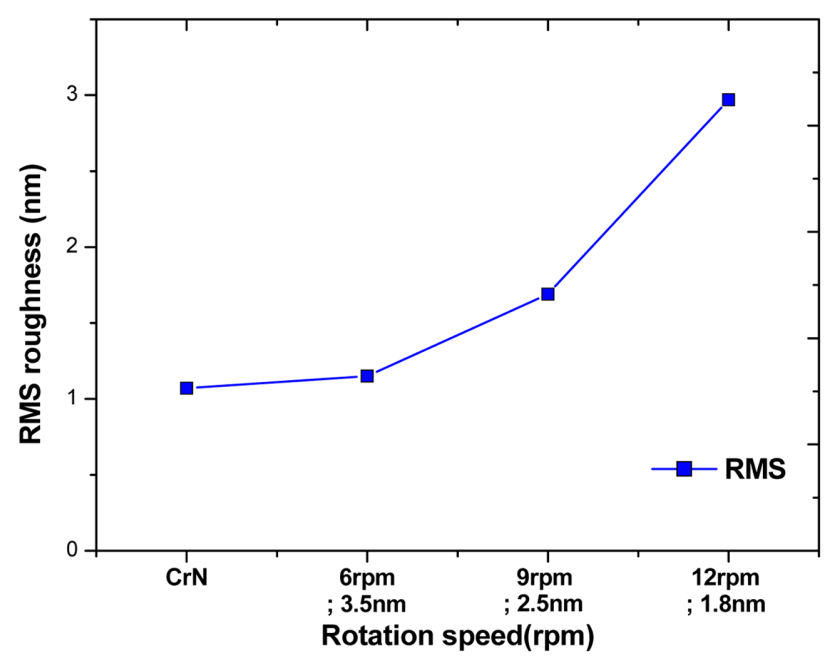

(b)

Fig. 7. (a) Surface morphologies and (b) RMS roughness of the CrN/AIN multilayer with various substrate rotation speeds. 


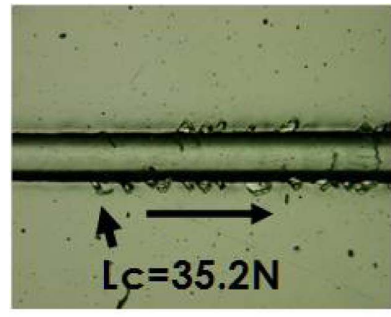

(a)

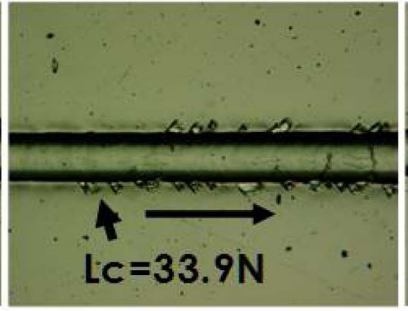

(b)

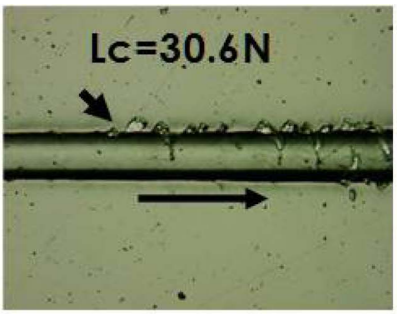

(c)

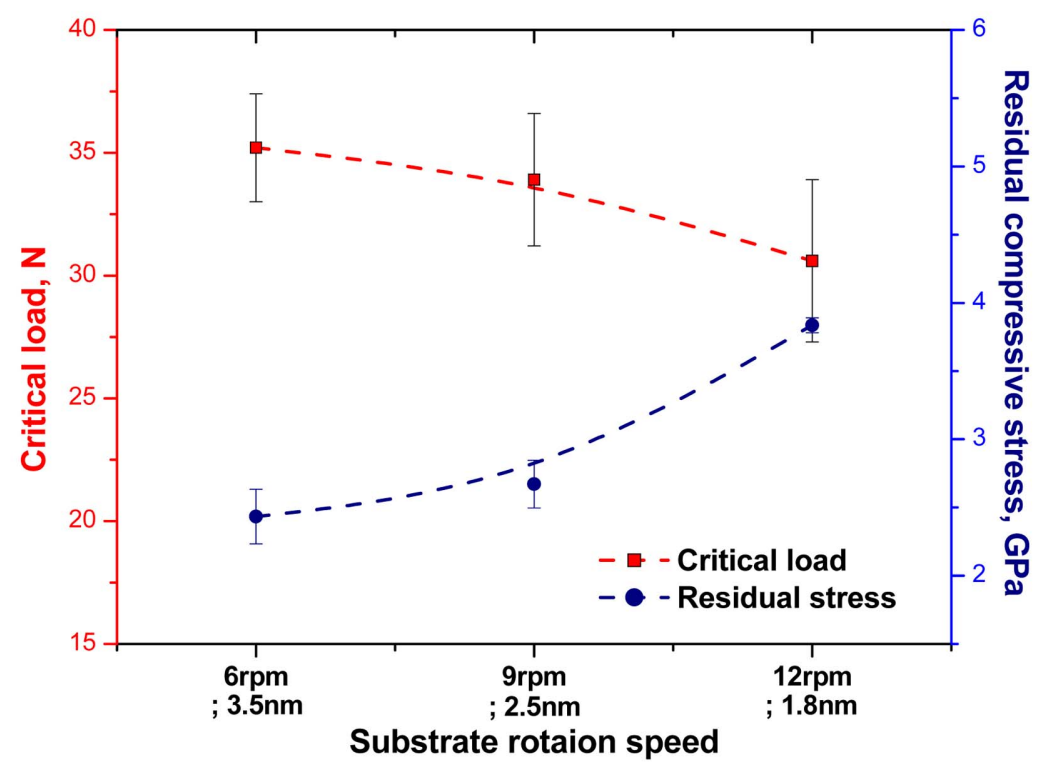

(d)

Fig. 8. The adhesion strength of CrN/AIN multilayer coatings with various bilayer periods of (a) $3.5 \mathrm{~nm}$, (b) $2.5 \mathrm{~nm}$, (c) $1.8 \mathrm{~nm}$ and (d) the relationship between the critical load (Lc) and the compressive residual stress with substrate rotation speed.

\section{Conclusions}

The CrN/AIN multilayer coatings with various bilayer thicknesses were successfully synthesized using an unbalanced magnetron sputtering method, and it was found that the hardness and thermal stabilities of the CrN/AIN multilayer coatings were dependent upon the bilayer period.

The hardness of the CrN/AlN multilayer coatings were measured and found to be in a range from approximately 24.3 to $37.6 \mathrm{GPa}$. A maximum hardness and elastic modulus of approximately 37.6 and $407 \mathrm{GPa}$, respectively, were obtained from the $\mathrm{CrN} /$ AIN multilayer coatings with bilayer period of $1.8 \mathrm{~nm}$. The maximum hardness was 1.54 times higher than that predicted by the rule of mixture from the $\mathrm{CrN}$ and AIN coating. The hardness of the multilayer coating increased as the bilayer period decreased, i.e. as the rotation speed increased. The Hall-Petch type relationship, hardness being related to (1/periodicity) ${ }^{-1 / 2}$, suggested by Lehoczky was confirmed for the $\mathrm{CrN} /$ AIN multilayer coatings with bilayer period close to the 5-10 $\mathrm{nm}$ range. In case of small bilayer period in the range of $<5 \mathrm{~nm}$, the hardness increase in the film could be explained by the coherency strain or lattice mismatch at the interface.

With decreasing bilayer period, the surface morphology of the films became rougher and the critical load of films for adhesion strength gradually decreased.

\section{Acknowledgements}

This work was supported by a grant from the Fundamental R\&D Program for Core Technology of Materials funded by the Ministry of Knowledge Economy, Republic of Korea. 


\section{References}

1. V. R. Parameswaran, J. P. Immarigeon, D. Nagy, Surf. Coat. Technol., 52 (1992) 251.

2. G. S. Kim, S. Y. Lee, J. H. Hahn, Surf. Coat. Technol., 171 (2003) 83.

3. O. Knotek, F. Löffler, H. J. Scholl, Surf. Coat. Technol., 45 (1991) 53.

4. T. Hurkmans, D. B. Lewis, J. S. Brooks, W. D. Münz, Surf. Coat. Technol., 86-87 (1996) 192.

5. H. B. Bhuvaneswarib, V. Rajagopal Reddyb, R. Chandramanic, G. Mohan Raoa, Applied Surface Science, 230 (2004) 88.

6. X. T. Zeng, S. Zhang, C. Q. Sun, Y. C. Liu, Thin Solid Films, 424 (2003) 99.

7. G. S. Kim, S. Y. Lee, Surf. Coat. Technol., 201 (2006) 4361.

8. M. Brizuela, A. Garcia-Luis, I. Braceras, J. I. Oñate, J. C. Sánchez-López, D. Martínez-Martínez, C. López-Cartes, A. Fernández, Surf. Coat. Technol., 200 (2005) 192.

9. L. Castaldi, D. Kurapov, A. Reiter, V. Shklover, P. Schwaller, J. Patscheider, Surf. Coat. Technol., 202 (2007) 781.

10. J. K. Park, Y. J. Baik, Surf. Coat. Technol., 200
(2005) 1519.

11. S. K. Tien, J. G. Duh, Thin Solid Films, 494 (2006) 173.

12. S. Tien, J. G. Duh, Thin Solid Films, 515 (2006) 1097.

13. S. K. Tien, J. G. Duh, J. W. Lee, Surf. Coat. Technol., 201 (2007) 5138.

14. B. S. Kim, G. S. Kim, S. Y. Lee, B. Y. Lee, Surf. Coat. Technol., 202 (2008) 5526.

15. J. Lin, J. J. Moore, B. Mishra, M. Pinkas, W. D. Sproul, Surf. Coat. Technol., 204 (2009) 936.

16. J. Lin, J. J. Moore, J. Wang, W. D. Sproul, Thin Solid Films, 519 (2011) 2402.

17. M. Murakami, A. Segmüller, K. N. Tu, Analytical Techniques for Thin Films, K. N. Tu, R. Rosenberg (ed.) Academic Press, New York, 27 (1988) 201.

18. Q. Yang, L. R. Zhao, J. Vac. Sci. Technol. A, 21 (2003) 558.

19. J. S. Koehler, Phys. Rev., B, 2 (1970) 547.

20. S. L. Lehoczky, J. Appl. Phys., 49 (1978) 5479.

21. J. Musil, J. Vlcek, Surf. Coat. Technol., 142-144 (2001) 557.

22. P. B. Barna, M. Adamik, Surf. Coat. Technol., 317 (1998) 27. 